\title{
From buying beds to upgrading an old rural hospital
}

\author{
YU LAP YIP
}

It was indeed quite tiring to consider working in another hospital so far away. I had worked in my present hospital for nearly eight years. It was so familiar that it seemed part of me. I had always worked in the city centre, having been born and bred there. I was used to working in hospitals a few minutes' walk away from my home, and perfectly adapted to the busy hospital life of operations, seminars, and grand rounds - and to metropolitan night life.

A friend of mine had recently been promoted to being the administrator of an old rural hospital that was in the early phase of expansion. It was near the border of Hong Kong, so far away that even sales representatives from the drug companies disliked going there. It had only a few doctors, old and retired. There was no

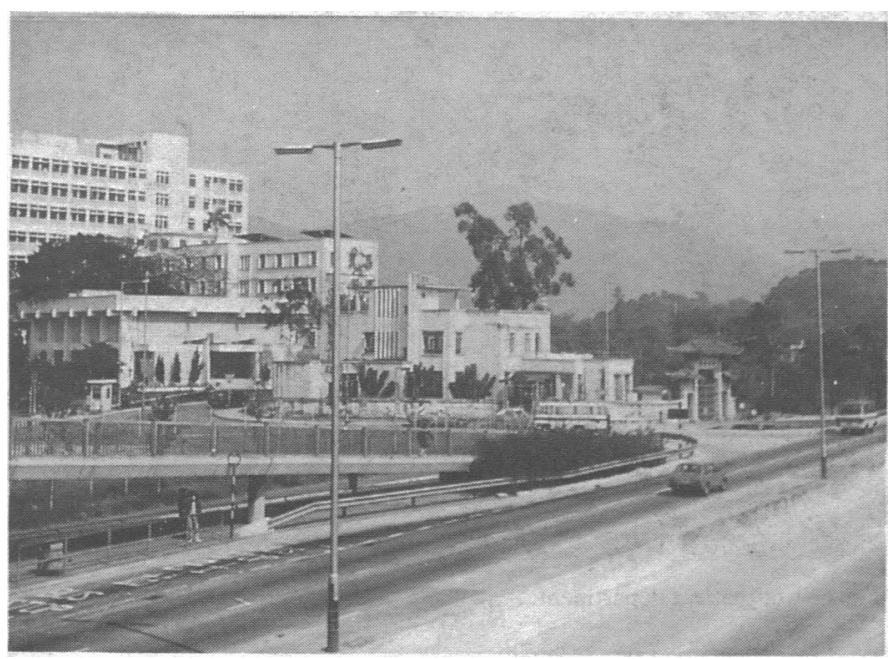

The newly built hospital.

specialty department: the specialists were all visiting doctors sent on rotation from urban hospitals. The hospital authority consisted of genuine country elders, in age as well as style. It was in desperate need of a more permanent doctor, of whatever specialty, so that at least they could have someone more qualified for the modernisation of the hospital. But advertising a high grade post for nearly a year had been completely futile. This I could easily understand, for even the visiting doctors were disgusted with their setup, as I was told by some of them who were my friends.

It was only after repeated telephone conversations that I eventually yielded and went there "just for a visit, no more." The hospital was amongst grassfields and huge fishponds, with lazy cows trotting under the sunshine and white cranes flying about. The few people walking around were mostly farmers. What a sight to someone used to working in an urban hospital with a catchment area population of 800000 . The building was of the old and forgotten style, three to four storeys high. There was, however, one building standing apart from the others from the top of which I could look across the border

Pok Oi Hospital, Yuen Long, NT, Hong Kong

YU LAP YIP, FRCSGLAS, head of department of surgery into China. The hospital was quite barren inside. The nurses were friendly but old and slow. The beds were worn out and occupied by senile people. The operating theatre had only two rooms and alarmingly few surgical instruments, old fashioned and seemingly not much used.

A perfect holiday resort, but no place for an active young doctor, was my conclusion after the visit. I forgot about it for nearly six months and busily continued my urban life.

My unit had many seniors. Getting promoted was out of the question. The stress of work made my ulcer pain recur and I had to resume my cimetidine. Several of my classmates in other specialties got promoted. All this made me feel the need for a change. My friend at the rural hospital rang, asking my advice on buying hospital beds, which was somewhat beyond her knowledge. They had still not been able to get any trained local chaps to work there and no untrained young doctors, of course, for it was not a training unit. So how could you expect a trained one to go there and do everything by himself? They were offering a senior post, with a bonus after the contract was completed. My recent bad luck prompted me to consider the idea more seriously, and I talked it over with one of my most respected seniors. Surprisingly he advised me to have a go.

\section{My new hospital}

Eventually I took the job, but tried very carefully to keep my lifestyle. I stayed living in the city centre so that I would not lose touch with the outside world. Each morning I had a journey equivalent to travelling from London to Salisbury Plain. I had no office of my own and had to sit in the hospital superintendent's room, and I chatted, often from 9 to 5 , with him. I left whenever he had visitors - usually angry, complaining, and well sized farmers. I often had to stand by and protect the superintendent, or just help share the chance of being beaten up. The hospital did not have a good name. Patients often demanded transfer, even for trivial complaints, and were usually sent across because of pressure from their relatives. The inevitable result was grumbles from the other hospital and such patients were often immediately discharged by their casualty department after a long trip. The result - we got a bad name with that hospital and some even more suspicious and angry patients. It was no good reassuring myself that I came from a very big and good hospital. However good you were, or thought you were, you had to face the fact that a single man cannot support a whole hospital's weakness.

The hospital superintendent was even more unhappy. I chose my job but he had been chosen to do his. It was absolutely no fun thinking of the status you would have as the head of a famous hospital instead of an infamous one.

We did not have much status, but we had lots of time. Every day we rang up drug firms asking them to send representatives with medical films - and good food of course - to entertain ourselves and our colleagues, who had not had such opportunities for many years. The films were not of much educational value, but they attracted lots of staff because it was new to them. We also rang up our friends, asking them to come and give talks. Transport and lunch were provided, of course. I was actually rather surprised to see the large audiences that gathered for what I regarded as trivial topics. Encouraged by the success we organised more lectures and film shows and even several talks on computer theory and application conducted by big computer firms.

Meanwhile we started our first big project in hospital expansion: buying patient beds. I had never been in an administrative job. I 
knew nothing about hospital beds other than the prop up frame, the wooden blocks for raising the end of the bed, and the variable height dialysis beds. I doubted whether my previous boss knew more because even he had not taken part in any bed buying.

We had no experience, but we had time. I drafted some of my dreams of an ideal bed. Also, as the beds were mostly used by nurses, I asked one of my previous intensive care unit nurses to look at the catalogues and make some comments. The problem was that we could not afford either what she recommended or my dream. I then looked for companies that had not approached us. This brought in some less well known ones, both more and less expensive.

As I did not know how to shop from catalogue specifications I asked the companies to bring in their beds for us to try. They were most reluctant to do it, for the cost of transporting a single bed to a customer who might not buy it is too high for most smaller companies. It was easier for those who had already sold a lot of beds in the area-we could see the beds and get references about their quality from people we knew. In fact I myself could be a referee.

The problem was that our budget had been drawn up years ago by someone unknown who really must have had no experience or insight at all (the rumour was that it was somebody who was the only one able to read the English catalogues then). It was so limited that if we were to buy the type of bed I commonly used (which was incidentally the only one I really knew) we could not afford even to buy the mattress. So we had to look at the very cheap beds. These were Japanese. Surprisingly, close as they were to our city, not a single bed had been sold, mainly because of the lack of a good reference. A close look at the colour catalogue, however, revealed that they were multifunction beds that could flex, elevate, and turn and were very mobile. The finish also looked marvellous. That none had been sold was probably because nobody dared to be the first to try. I thought so, because I also dared not try. But I was forced to.

Eventually they sent one bed across. We examined it with a team: doctors to look at its capabilities; nurses at ease of operation; amahs for ease of cleaning and transport; mechanics for sturdiness; and administrative officers for patient safety and acceptance. We had to do it this way because we had no experience of buying. With the same team we also looked at beds which we obviously could not afford. We wanted to gain knowledge for assessing the defects of those which we could afford. Also we wanted to advertise-to our staff and to the suppliers-that the hospital was starting improvements. We examined more expensive beds in other hospitals and surprisingly many were not up to our standard, even in some big new teaching hospitals. We began to gain confidence. At least we now knew more than many consultants and administrators. We also discovered that the little known Japanese company we faced was in fact the biggest in Japan, and bigger than many "famous" bed companies in our locality.

But as one proverb said aptly, "Even a foreign tiger is no match for a local ant." The company still had no local reference and our increasing knowledge did not make us richer. There could be no solution except asking the local agent to cut their price. So telexes and telegrams went to and fro, and the price of our beds dropped again and again. The local agent got more and more anxious as the wild dream became more and more real. As the news spread more companies began to compete and more and more salesmen began to call. As I said, we had the time, and we in fact needed them to while away our boring office hours. That was why this battle dragged on, waxing and waning for nearly nine months.

\section{A new concept of purchasing}

But time was getting more valuable. By now my new operating theatre had been completed. It was not big, but I had to start buying surgical instruments, and with the habit I had acquired from bed purchase I studied each catalogue from first to last page. I had no operating theatre sister to help me out, or to be blamed. I had never had to buy any instruments before: that was all my boss's job-or rather the operating theatre sister's job. My boss's job was just to sign his name, and our job to accept or criticise behind their backs.
Now I did all three jobs. I had to ring up every hospital to ask my classmates or nurses I knew about suppliers, different brands, and what standard surgical sets they were using and so on-with the result that I got even more to read and ponder.

I changed my instrument plan five times. I could never draft a plan that enabled me to buy even the most economical version of the other hospitals' standard set up. Money was the problem again. I finally threw them all away. After all, I would be the only surgeon there. The instruments would be used by me alone at least for the next three or four years, because they would not be able to recruit another fool. We obviously could not carry out operations requiring lots of perioperative care and manpower. So why cling to the pattern of hospitals with many experienced surgeons? Suddenly the budget looked more adequate.

My experience with bed purchase helped me again. The fact that the beds of famous hospitals were not really good or no longer satisfactory was educational. If we could even be slightly wiser than

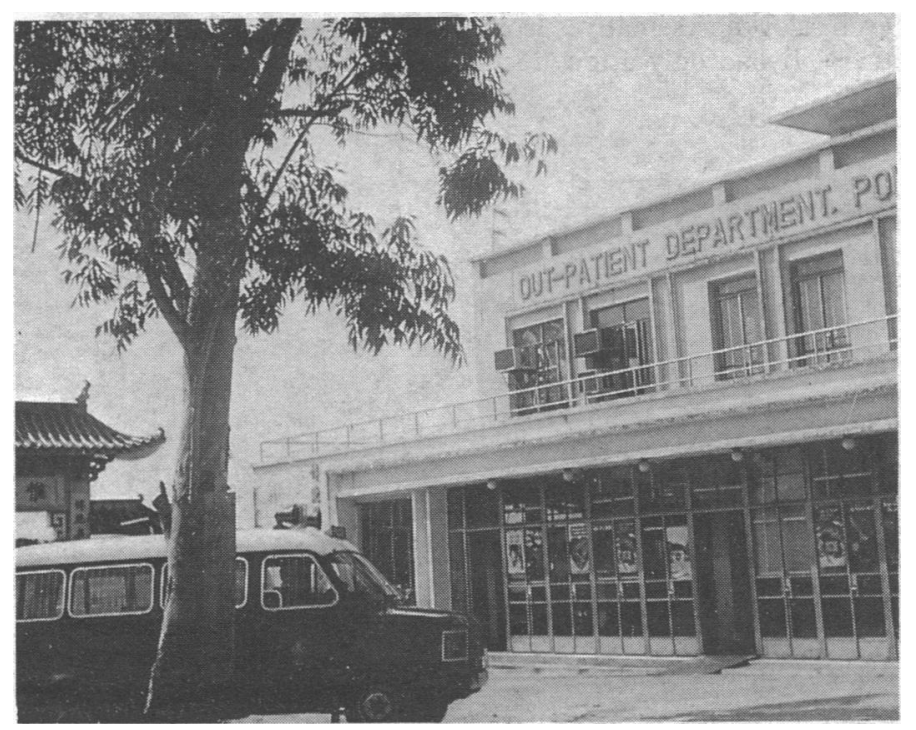

The new outpatient department.

them over beds, we could do it over instruments. I began to look into international new product catalogues and the "untouchable" ones that my boss always threw away because they were too expensive. They were on electronic video endoscopy, endourology, ECG with interpreting computer software, zip chains for wound closure, and non-invasive cardiac output monitors. We could not always only go by the past experience of others: we were planning a hospital for the present and future, and the foundations must be laid down now when we were not much hindered by tradition, a large recurrent expenditure, and lots of routine work. Moreover, we had our local needs and limitations.

I went to the university library and did a literature search. I glanced at relevant papers of the past 10 years. I was most ashamed to find many of my ideas behind the times. I also found out that there were in fact journals on medical technology and medical consumers' guide type articles, which I had not known about before.

This was, I think, because doctors only read up journals of their own specialty, which are usually slower to produce information about technology than equipment journals or technology journals We also seldom read journals devoted to product comparison, because we are excluded from purchasing until we are at the top. This does not give good training. It leads us to a biased view of those few products that we know and we tend to neglect new products and new companies. I do not mean that we should gamble with a limited health budget, but old and reliable companies are usually more expensive and more conservative in their designs. Smaller companies are more flexible in price and in bringing in new ideas. As 
buyers we should not just play safe and be bound by our preconceptions.

It is precisely because of the scarcity of health funds that we should buy not only like doctors: we should also buy like someone buying a video camera for his own use. As doctors, we do not bargain: we just demand more funds. We do not look around but tend to buy whatever is recommended in the seminars and journals without tailoring it to our own requirements. If we are buying our own video camera we think of our pocket first. Then we ask our friends. We walk around the shops, and test the cameras. We read up the photography journals. Another thing to remember when buying for a hospital with a large budget is that the annual clearance sales and price adjustments, reductions on old products, and fluctuation of international currencies can all significantly affect what we can buy. You have to look beyond the purely clinical viewpoint.

\section{After one year}

Meanwhile I started buying cardiac monitors, ventilators, infusion pumps and operating microscopes. I was now more experienced and better informed. Salesmen came regularly, on their own initiative. I now knew which were the good or bad guys. I had good contacts with information sources in other hospitals. I was more used to writing direct to big centres and world authorities for their opinion. I had even once gone on a trip to the manufacturers and to the Institute of Urology in Shaftesbury Avenue-my Disneyland-to discuss my problems and try out unfamiliar instruments. I now knew how to bargain over prices and, more importantly, how to ask for more money from the health authority and public funds. Having watched for over a year how medical products changed and developed I had more idea of the potential of a new product. The knowledge I had gained from the talks on computers I had organised for fun helped me a lot in appreciating these recent changes, which were mostly related to microprocessor technology.

Now the hospital has changed a lot. The angry complaining farmers turn up only very occasionally. Requests for transfer are much less frequent and we no longer feel humiliated when we refer patients. We are now getting more energetic doctors as the news of modernisation spreads through our friends the salesmen. My operating list is now longer than that of my previous hospital. We are doing some general operations such as cholecystectomy and thyroidectomy which have never been done here before. At first the nurses crowded round to watch; now they just take it as a matter of course. We also do some minor operations that are quite new even to me. On the other hand medical films and lectures are less well attended - they are no longer new to us and our workload is much heavier. As for computers, we got our first set of computers donated, complete with graphics tablet and light pens. We started some small trials, and have already submitted a few papers to medical journals. Because we do not have decades of bulky old files to be tackled I started redesigning patient records for future computer storage. I never dreamt of anything like this in my former hospital-I was simply too preoccupied and too much in a routine.

Now my life is far busier than before, but I feel much happier. I can no longer learn from my colleagues as readily as before, but I know that I learn a lot of other useful things, though in a much harder way. I have attended several courses on economics, accounting, marketing, and continuing medical education, which I quite despised in the past. I read journals less frequently but more regularly and seriously, spurred by thirst for knowledge and fear of being left behind rather than for tackling the coming week's seminar or grand round.

Each member of the bed purchasing team is busy with his many new commitments, but we retain our team spirit. The old friend who brought me here has left for another hospital. She was happy to leave the hospital in the hands of this now more mature team of bed purchasers. As for the beds, we eventually got them, after nearly 10 months. They are four-section stainless steel ones, with epoxy resin coating, that can be raised for peritoneal dialysis, for sitting up, and for the Trendelenburg position; castors with three locking systems; collapsible side rails that are safe to the fingers; and a complete set of flame resistant mattress, overbed table, and IV poles. All easily cleaned and perfectly manoeuvrable, even for a tiny nurse-and all for the same price that we could originally afford for a barren empty bed with nothing else. The Japanese got only half the contract, the other half going to an Austrian company, also new to the market. As for our friend the agent for the Japanese beds, he has been promoted to being the medical equipment executive of that company and is already selling more beds to other hospitals.

\section{Down on the health farm}

\section{JANE DAWSON}

Few of the guests at the health farm resembled the nineteenth century Englishman in the series of humorous etchings hung immediately opposite the dining room door. He was shown carrying his embonpoint in a wheelbarrow on to the ferry having enjoyed "la cuisine Française." Most of the guests were women of average size aged 30 or more who were having a break from the family; the men in general ran their own businesses, tended to be more obviously overweight, and were concerned about heart disease.

The nucleus of the health farm was a large Victorian house set in landscaped grounds. The greeting in tessella in the bicycle lined porch was appropriately "Salve." Modern wings had been added to accommodate 150 people. There was also a 12.5 metre swimming

British Heart Journal, London WC1H 9JR

JANE DAWSON, BSC, technical editor pool with steamy plate glass windows, through which a band of Muscovy ducks peered in enviously.

On arrival I had a consultation with one of the many ladies in white. I was weighed and had my blood pressure measured; she also asked me if I was on any medication or had any back problems or varicose veins. When asked the purpose of my stay-weight loss, relaxation, or fitness-I should have added curiosity to the list.

Guests wandered around in the hot house atmosphere in dressing gowns and track suits. The formidable matrons who arrived in fur coats seemed more sympathetic in déshabillé-the towelling robe is a great leveller. My room had a wash basin and toilet. The remote controlled television did not encourage unnecessary physical activity.

When I went to join the early morning stroll, I found that none of the 50 or so other guests was prepared to brave the February weather. The gym instructor who accompanied me on a brisk walk over the surrounding National Trust heathland described the hall as "not for the purists, you don't have to be a galley slave all week." The exercise, weight training, and relaxation classes were better 